\title{
Effects of a priority-based dual task on gait velocity and variability in older adults with mild cognitive impairment
}

\author{
Jihye Lee, Seungha Park* \\ Department of Kinesiology and Sports Studies, Ewha Womans University, Seoul, Korea
}

The purpose of this study to investigate how gait velocity and variability were affected by dual task prioritization in older adults with normal cognitive function and older adults with mild cognitive impairment (MCI). Eight older adults with $\mathrm{MCl}$ and eight cognitively normal older adults performed a walking task under usual walking with no dual task (usual gait), walk while counting backward from 100 by ones with no priority on task (no priority), walk and count while instructed to prioritize gait task (gait priority), and walk and count while instructed to prioritize the cognitive task (cognitive priority). The $\mathrm{MCI}$ group showed significantly slower walking speed than the normal group in the no priority condition, but no difference between both group in the usual gait condition, and they almost 3 times greater gait variability in the no priority condition than the normal group. For the effect of priority instructions, $\mathrm{MCl}$ group showed a dual-task cost to gait velocity almost 2 times higher than that of the normal group in the no priority condition, but the cost was almost three times higher in both gait and cognitive priority conditions. Although there was no interaction effect for gait variability, $\mathrm{MCl}$ group tended to be more influenced by dual task prioritization than the normal group. Our findings confirmed that the priority-based dual task paradigm is a valid way to assess gait characteristics of people with cognitive problems.

Keywords: Mild cognitive impairment, Priority, Dual task, Gait

\section{INTRODUCTION}

Mild cognitive impairment (MCI) is considered a transitional phase between normal aging and dementia (Petersen, 2004; Winblad et al., 2004). People with MCI experience problems related to mobility as well as cognitive functioning (Eggermont et al., 2010), which increase the risk of falls. Functional impairment of gait is one of the most consistent predictors of falls; thus, it is important to evaluate gait function in older adults with MCI (Muir et al., 2012).

Dual task testing is useful for examining activities of daily living that require two or more tasks to be performed simultaneously, and can represent various situations in which falls may occur (Lim et al., 2017; Yogev-Seligmann et al., 2008). In addition, this type of testing has been shown to be useful for identifying gait problems associated with cognitive functions. In gait research, a dual task study requires simultaneously carrying out walking and cognitive tasks, so that the characteristics of walking in the dual task condition can be compared with those in the usual walking condition. In general, it has been reported that the influence of cognitive task interference on gait is greater in people with MCI than in people with normal cognition, and that the gait speed is lower and the gait variability higher in dual task conditions (Gillain et al., 2009; Maquet et al., 2010; Montero-Odasso et al., 2012).

Bloem et al. (2006) reported that older adults with normal cognitive function use a "posture first" strategy to maintain walking and balance as the tasks become more complicated in dual task trials. However, they found that Parkinson disease patients used a "posture second" strategy, making it difficult to maintain balance and eventually leading to falls. Thus, it can be seen that the prioritization strategy in the dual task affects walking functions.

There is a conflict between tasks during performance of a dual task, especially when informational processing is limited due to cognitive functional problems such as MCI. Therefore, gait function depends on how the priority is set (Pashler, 1994; Tombu and
${ }^{*}$ Corresponding author: Seungha Park (10 https://orcid.org/0000-0002-0512-5035 Department of Kinesiology and Sports Studies, Ewha Womans University, 52 Ewhayeodae-gil, Seodaemun-gu, Seoul 03760, Korea

Tel: +82-2-3277-2588, Fax: +82-2-3277-2846, E-mail: seungpark@ewha.ac.kr Received: August 13, 2018 / Accepted: October 5, 2018
This is an Open Access article distributed under the terms of the Creative Commons Attribution Non-Commercial License (http://creativecommons.org/licenses/by-nc/4.0/) which permits unrestricted non-commercial use, distribution, and reproduction in any medium, provided the original work is properly cited. 
Jolicoeur, 2003). "Priority" means paying attention to an exercise or cognitive task first when performing a dual task. Recently, Yogev-Seligmann et al. (2010) compared the gait characteristics of young adults and older adults in relation to their priorities while performing the dual task. They found that walking speed decreased in cognitive priority conditions, but the effect was less dramatic for older adults than for young adults. Further, unlike young adults, older adults showed greater variability in walking in both the cognitive and gait priority conditions. These results suggest that flexibility in allocating attention decreases with aging.

The older adults with MCI are at increased risk of falling due to decreased cognitive function. Nevertheless, there is a lack of research on dual task performance in older adults with $\mathrm{MCI}$ in Korea. Therefore, we conducted this study to learn whether there is a difference in gait characteristics in a dual task condition between older adults with normal cognitive function and older adults with $\mathrm{MCI}$, and to investigate how gait characteristics were affected by dual task prioritization in both groups.

\section{MATERIALS AND METHODS}

\section{Participants}

Eight older adults with MCI and eight cognitively normal older adults participated in the study. All participants had no experience of falling in the past and participated voluntarily. The subjects with $\mathrm{MCI}$ were clinically diagnosed with mild cognitive disorder in hospitals within the previous 3 years. Before the experiment, they also were administered the Korean version of the Mini-Mental State Examination (MMSE-K) to evaluate the cognitive functioning. Descriptive statistics on the ages and MMSE-K mean scores of the MCI and normal groups are shown in Table 1. This study was approved by ethic review board (approval number: 139-5) and all participants provided informed consent.

\section{Procedure}

The task for this study was to walk a 10-m-long path in the laboratory twice at a comfortable pace under the following four

Table 1. Age and MMSE-K score of participants

\begin{tabular}{lcc}
\hline Group & Age $(y r)$ & MMSE-K \\
\hline Normal $(n=8)$ & $66.1 \pm 1.64$ & $28.1 \pm 0.83$ \\
$\mathrm{MCl}(\mathrm{n}=8)$ & $66.5 \pm 1.85$ & $21.0 \pm 0.76$ \\
\hline
\end{tabular}

Values are presented as mean \pm standard deviation.

Normal is $>24$ and $\mathrm{MCl}$ is defined as scores between 20 and 23.

MMSE-K, Korean version of the Mini-Mental State Examination; MCI, mild cognitive impairment. conditions: (1) usual walking with no dual task (usual gait), (2) walk while counting backward from 100 by ones (cognitive task) with no explicit instruction on the priority of either task (no priority), (3) walk and count while instructed to prioritize the gait task (gait priority), and (4) walk and count while instructed to prioritize the cognitive task (cognitive priority). Participants were asked to "focus on the walking task" in the gait priority condition, and to "focus on counting backwards form 100 by ones" in the cognitive priority condition. The two priority conditions were counterbalanced across participants to minimize the effect of order.

To obtain kinematic data, 21 reflective markers were attached to various locations on the pelvis and lower limbs of the subjects. Data were collected at $60 \mathrm{~Hz}$ using a three-dimensional analysis system with six cameras, and analyzed using OrthoTrak 6.5 (EVa/ EVaRT software, Motion Analysis Corp., Santa Rosa, CA, USA), excluding the first $2 \mathrm{~m}$ and the last $2 \mathrm{~m}$ of the walking path to avoid acceleration and deceleration.

\section{Dependent variables and data analysis}

The dependent variables were gait velocity, gait variability, and dual-task cost to gait velocity and variability. Gait velocity is a valid and reliable indicator of mobility and fall risk. Gait variability was analyzed as stride time variability, which quantifies the automaticity of gait from one stride to the next during steadystate walking (Muir et al., 2012). Gait variability was quantified using the coefficient of variation (CV [\%]; $\mathrm{CV}=$ [standard deviation $/$ mean $] \times 100 \%)$. Dual-task cost was calculated as a percentage for each gait parameter as ([\{single task value- dual task value\}/ mean single task value] $\times 100 \%$ ).

Repeated measure two-way analysis of variance (ANOVA) was performed to evaluate the effects of group (cognitively normal vs. $\mathrm{MCI}$ ) and task condition (usual gait vs. no priority and no priority

Table 2. Results of two-way analysis of variance on gait parameters in older adults with normal cognition and mild cognitive impairment

\begin{tabular}{|c|c|c|c|c|c|}
\hline \multirow{2}{*}{ Variable } & \multicolumn{2}{|c|}{ Condition } & \multirow{2}{*}{$\begin{array}{l}\text { Within } \\
\text { group } \\
\text { effect }\end{array}$} & \multirow{2}{*}{$\begin{array}{l}\text { Between } \\
\text { group } \\
\text { effect }\end{array}$} & \multirow{2}{*}{$\begin{array}{l}\text { Interaction } \\
\text { (group } \times \\
\text { condition) }\end{array}$} \\
\hline & Usual gait & No priority & & & \\
\hline \multicolumn{3}{|c|}{ Gait velocity (cm/sec) } & $<0.001$ & 0.070 & 0.034 \\
\hline Normal & $105.71 \pm 6.43$ & $91.97 \pm 8.87$ & & & \\
\hline $\mathrm{MCl}$ & $99.75 \pm 17.84$ & $72.86 \pm 18.45$ & & & \\
\hline Gait variability (\%) & & & $<0.001$ & 0.042 & 0.007 \\
\hline Normal & $2.77 \pm 1.05$ & $4.49 \pm 1.90$ & & & \\
\hline $\mathrm{MCl}$ & $2.44 \pm 0.99$ & $11.21 \pm 6.84$ & & & \\
\hline
\end{tabular}

Values are presented as mean \pm standard deviation. $\mathrm{MCl}$, mild cognitive impairment. 
Table 3. Results of two-way analysis of variance on gait parameters in older adults with normal cognition and mild cognitive impairment

\begin{tabular}{|c|c|c|c|c|c|c|}
\hline \multirow{2}{*}{ Variable } & \multicolumn{3}{|c|}{ Condition } & \multirow{2}{*}{ Main effect } & \multirow{2}{*}{$\begin{array}{l}\text { Between } \\
\text { group effect }\end{array}$} & \multirow{2}{*}{$\begin{array}{c}\text { Interaction } \\
\text { (group } \times \text { condition) }\end{array}$} \\
\hline & No priority & Gait priority & Cognitive priority & & & \\
\hline Gait velocity (cm/sec) & & & & $<0.001$ & 0.002 & \\
\hline Normal & $91.97 \pm 8.87$ & $88.84 \pm 7.09$ & $87.71 \pm 7.88$ & & & 0.005 \\
\hline $\mathrm{MCl}$ & $72.86 \pm 18.45$ & $54.38 \pm 24.62$ & $57.46 \pm 18.01$ & & & \\
\hline Gait variability (\%) & & & & 0.009 & $<0.001$ & \\
\hline Normal & $4.49 \pm 0.19$ & $5.31 \pm 3.21$ & $12.07 \pm 6.12$ & & & 0.122 \\
\hline $\mathrm{MCl}$ & $11.21 \pm 6.80$ & $25.48 \pm 12.95$ & $24.29 \pm 14.16$ & & & \\
\hline Dual task cost to gait velocity & & & & $<0.001$ & 0.003 & \\
\hline Normal & $13.00 \pm 7.81$ & $15.96 \pm 6.31$ & $17.02 \pm 7.55$ & & & 0.004 \\
\hline $\mathrm{MCl}$ & $26.95 \pm 13.58$ & $45.48 \pm 20.11$ & $42.39 \pm 18.89$ & & & \\
\hline Dual task cost to gait variability & & & & 0.010 & $<0.001$ & \\
\hline Normal & $61.83 \pm 43.56$ & $111.47 \pm 115.27$ & $334.49 \pm 229.46$ & & & 0.134 \\
\hline $\mathrm{MCl}$ & $359.12 \pm 255.27$ & $944.11 \pm 534.21$ & $895.49 \pm 565.32$ & & & \\
\hline
\end{tabular}

Values are presented as mean \pm standard deviation.

$\mathrm{MCl}$, mild cognitive impairment.

vs. gait priority vs. cognitive priority). The statistical significance threshold was set at $P<0.05$.

\section{RESULTS}

\section{Effect of a dual task}

The results of repeated measures ANOVAs for gait velocity and gait variability, with factors of group (MCI vs. normal) and condition (usual walking vs. dual task with no priority) are presented in Table 2. For both parameters, there were highly significant main effects of condition. For gait velocity, there was a marginal but not significant main effect of group; for gait variability, the effect of group was significant, although marginally so. For both parameters, significant interactions were found between group and condition. Post boc tests showed that the MCI group did not differ significantly in gait velocity from the normal group in the usual walking condition $(P=0.389)$, but the $\mathrm{MCI}$ group showed significantly slower walking speed than the normal group in the dual task condition $(P=0.019)$. For gait variability, the $\mathrm{MCI}$ group was much more strongly affected by the dual task condition than the normal group. Specifically, the MCI showed almost 3 times greater gait variability in the no priority dual task condition than the normal group $(P=0.028)$.

\section{Effects of priority instructions}

Table 3 shows the results of repeated measures ANOVAs for gait velocity, gait variability, and the dual-task cost to each of these, with factors of group (MCI vs. normal) and condition (no priority, gait priority, cognitive priority). Significant main effects of both group and condition were found for all four parameters. Statistically significant interactions were found for gate velocity and the dual-task cost to gait velocity, but not for the parameters relating to gait variability (Table 3). Post hoc testing showed that the difference in velocity between the two groups was greater in both the gait priority and cognitive priority conditions than in the no priority condition. These results were similar for the dual-task cost to gait velocity. The MCI group showed a dual-task cost to gait velocity almost 2 times higher than that of the normal group in the no priority condition, but the cost was almost three times higher in both priority conditions.

For gait variability and dual task cost to gait variability, MCI group showed significantly higher than normal group, and both parameters were greater in both priority conditions than in the no-priority condition. Although there was no interaction effect, MCI tended to be more influenced by dual task prioritization than the normal group.

\section{DISCUSSION}

This study investigated the effects of task priority on gait performance in older adults with MCI and older adults with normal cognition in a dual task condition. In accordance with earlier studies (Muir et al., 2012; Yogev-Seligmann et al., 2010), performance of a dual task reduced gait speed and increased gait variability in both groups. Interestingly, we observed that the MCI group was more negatively influenced by priorities in the dual 
task than the normal group, and it seems this effect tended much larger on gait variability than on gait speed.

Both groups in our study had a normal gait velocity $(>1 \mathrm{~m} / \mathrm{sec})$ in the single task condition. In the dual task condition, however, both groups showed velocities less than $1 \mathrm{~m} / \mathrm{sec}$. In more detail, although the normal group maintained a speed of more than 0.8 $\mathrm{m} / \mathrm{sec}$ in all dual task conditions, the MCI group dropped to a speed of almost $0.5 \mathrm{~m} / \mathrm{sec}$ when a task priority was given.

To assess gait variability, we measured the relationship of stride to stride time. The variability of the stride time provides an interesting result for understanding the cognitive control of gait and the risk of falls (Montero-Odasso et al., 2012). High stride time variability has been shown to predict future falls in cases where gait velocity failed to distinguish those who fell and those who did not (Hausdorff et al., 2001; Montero-Odasso et al., 2012). In light of a previous study (Callisaya et al., 2010), a large variability in walking patterns means a decline in walking control ability and a decrease in the stability of walking, which can lead to an increased risk of falls.

We predicted that the gait variability would be higher in the cognitive priority condition than in the gait priority condition. As expected, the MCI group was more variable than the normal group, and the variability was highest in the cognitive priority condition. Although there was no significant interaction effect, it is interesting to note that the mean value of variability for normal group was higher in the cognitive priority condition than in the gait priority condition, but there was no difference between the two priority conditions in the subjects with MCI. This result can be interpreted from the following two perspectives. First, both the MCI and normal groups had difficulty using a "posture first" strategy when priority was given to cognitive task, and the difficulty for the MCI group was much greater. Second, for the MCI group, paying attention to walking itself in the gait priority condition can generate a greater cognitive load, which can interfere with the automaticity of walking movement.

Our findings confirmed that the priority-based dual task paradigm is a valid way to assess gait characteristics of people with cognitive problems. Additionally, we found that gait variability is more sensitive to task priority than gait velocity, and could be used as a predictor of fall risk in older adults with $\mathrm{MCI}$, as mentioned by Montero-Odasso et al. (2012). Finally, we expect the priority-based dual task paradigm to show potential as an evaluation method for clinically judging MCI in the field. In this study, we did not measure the spatial relationship of major joints. Further studies are needed to explore how the coordination between major joints is affected by priority-based dual task in people with and without MCI.

\section{CONFLICT OF INTEREST}

No potential conflict of interest relevant to this article was reported.

\section{REFERENCES}

Bloem BR, Grimbergen YA, van Dijk JG, Munneke M. The "posture second" strategy: a review of wrong priorities in Parkinson's disease. J Neurol Sci 2006;248:196-204.

Callisaya ML, Blizzard L, Schmidt MD, McGinley JL, Srikanth VK. Ageing and gait variability - a population-based study of older people. Age Ageing 2010;39:191-197.

Eggermont LH, Gavett BE, Volkers KM, Blankevoort CG, Scherder EJ, Jefferson AL, Steinberg E, Nair A, Green RC, Stern RA. Lower-extremity function in cognitively healthy aging, mild cognitive impairment, and Alzheimer's disease. Arch Phys Med Rehabil 2010;91:584-588.

Gillain S, Warzee E, Lekeu F, Wojtasik V, Maquet D, Croisier JL, Salmon E, Petermans J. The value of instrumental gait analysis in elderly healthy, MCI or Alzheimer's disease subjects and a comparison with other clinical tests used in single and dual-task conditions. Ann Phys Rehabil Med 2009;52:453-474.

Hausdorff JM, Rios DA, Edelberg HK. Gait variability and fall risk in community-living older adults: a 1-year prospective study. Arch Phys Med Rehabil 2001;82:1050-1056.

Lim J, Chang SH, Lee J, Kim K. Effects of smartphone texting on the visual perception and dynamic walking stability. J Exerc Rehabil 2017;13: 48-54.

Maquet D, Lekeu F, Warzee E, Gillain S, Wojtasik V, Salmon E, Petermans J, Croisier JL. Gait analysis in elderly adult patients with mild cognitive impairment and patients with mild Alzheimer's disease: simple versus dual task: a preliminary report. Clin Physiol Funct Imaging 2010;30: 51-56.

Montero-Odasso M, Muir SW, Speechley M. Dual-task complexity affects gait in people with mild cognitive impairment: the interplay between gait variability, dual tasking, and risk of falls. Arch Phys Med Rehabil 2012;93:293-299.

Muir SW, Speechley M, Wells J, Borrie M, Gopaul K, Montero-Odasso M. Gait assessment in mild cognitive impairment and Alzheimer's disease: the effect of dual-task challenges across the cognitive spectrum. Gait Posture 2012;35:96-100.

Pashler H. Dual-task interference in simple tasks: data and theory. Psychol 
Bull 1994;116:220-244.

Petersen RC. Mild cognitive impairment as a diagnostic entity. J Intern Med 2004;256:183-194.

Tombu M, Jolicoeur P. A central capacity sharing model of dual-task performance. J Exp Psychol Hum Percept Perform 2003;29:3-18.

Winblad B, Palmer K, Kivipelto M, Jelic V, Fratiglioni L, Wahlund LO, Nordberg A, Bäckman L, Albert M, Almkvist O, Arai H, Basun H, Blennow K, de Leon M, DeCarli C, Erkinjuntti T, Giacobini E, Graff C, Hardy J, Jack C, Jorm A, Ritchie K, van Duijn C, Visser P, Petersen RC.
Mild cognitive impairmen-beyond controversies, towards a consensus: report of the International Working Group on Mild Cognitive Impairment. J Intern Med 2004;256:240-246.

Yogev-Seligmann G, Hausdorff JM, Giladi N. The role of executive function and attention in gait. Mov Disord 2008;23:329-342.

Yogev-Seligmann G, Rotem-Galili Y, Mirelman A, Dickstein R, Giladi N, Hausdorff JM. How does explicit prioritization alter walking during dual-task performance? Effects of age and sex on gait speed and variability. Phys Ther 2010;90:177-186. 